\title{
PENATAAN LAMPU PENERANGAN JALAN UMUM SEBAGAI UPAYA MENGURANGI BIAYA ENERGI LISTRIK
}

\author{
Bambang Winardi' ${ }^{1)}$, Imam Santoso ${ }^{2)}$, Erlin Dolphina3) \\ ${ }^{1,2)}$ Departemen Teknik Elektro, Universitas Diponegoro Semarang \\ ${ }^{3)}$ Teknik Informatika, Universitas Dian Nuswantoro, Semarang \\ Email : bbwinar@gmail.com, imamstso@elektro.undip.ac.id, erlindolphina@gmail.com
}

\begin{abstract}
Abstrak
Pertumbuhan ekonomi dan jumlah penduduk yang semakin besar, menyebabkan meningkatnya kebutuhan akan fasilitas-fasilitas umum, salah satunya adalah sarana dan prasarana jalan yang memadai.Banyaknya angka kejahatan maupun kecelakaan lalu lintas di jalan, sebagian disebabkan karena kurangnya pencahayaan pada jalan yang kurang memadai.

Kurangnya pencahayaan ini disebabkan oleh pengaturan jumlah penerangan yang kurang sesuai dengan standar yang berlaku Selain itu, pengaturan penerangan jalan serta banyaknya pemasangan lampu penerangan jalan yang dipasang tanpa ijin oleh masyarakat menyebabkan semakin besarnya biaya penerangan jalan umum yang dibebankan pada pemerintah daerah setempat, karena kebanyakan lampu-lampu tersebut tidak mempunyai meter unutk menghitung konsumsi dayanya. Dengan metode mengoptimalkan penerangan jalan yang memenuhi kebutuhan kelas jalan sesuai kebutuhan, maka selain dapat mengurangi beban pengeluaran pemerintah daerah dalam tagihan penerangan jalan. Dari hasil pengujian program perhitungan didapatkan program penataan lampu penerangan jalan dengan menggunakan Kwh Meter akan menghasilkan biaya energi lebih rendah dari pada tanpa menggunakan Kwh Meter.
\end{abstract}

Kata kunci: Cahaya, LPJU, Kualitas Penerangan Jalan Umum

\section{PENDAHULUAN}

Semakin berkembangnya suatu daerah perkotaan di seluruh Indonesia menuntut penambahan fasilas umum yang dapat dimanfaatkan oleh masyarakat. Pemasangan penerangan jalan di fasilitas umum dari jalan perkotaan sampai di jalan pedesaan menuntut penambahan penerangan untuk jalan dengan meningkatnya pengguna atau pengguna jalan. Sarana yang paling dibutuhkan masyarakat sekarang adalah penambahna Lampu Penerangan Jalan Umum (LPJU). LPJU yang terpasang sekarang umumnya terutama yang terpasang didaerah banyak yang belum memakai Kwh Meter. Jenis lampu yang digunakan kebanyakkan masih terpasang jenis lampu yang tidak memenuhi syarat berdasarkan jenis kelas jalan (lampu mempunyai daya ( watt) besar akan tetapi nilai lux yang kecil), demikian juga dengan maraknya pemasangan lampu jalan umum tanpa ijin yang dilakukan oleh sebagian masyarakat. [2]

Pihak Pemerintah Kota sebagai penanggung jawab keberadaan Lampu Penerangan Jalan Umum (LPJU) dalam mengitung jumlah besarnya pemakaian energi listrik yang terpakai LPJU adalah dengan cara mencatat pemakaian energi listrik dalam sebulan yang tertera di $\mathrm{kWh}$ meter bagi Lampu Penerangan Jalan Umum yang sudah terpasang alat $\mathrm{kWh}$ meter dan untuk Lampu Penerangan Jalan Umum yang belum terpasang $\mathrm{kWh}$ meter pencatatan penggunaan energi listrik berdasarkan peraturan pemerintah kota setempat yang ditetapkan. Pembayaran tagihan listrik untuk LPJU didapatkan oleh pemerintah kota/daerah setempat dari pungutan pajak penerangan jalan yang tertera di rekening tagihan listrik pelanggan sebesar $8 \%$ dari biaya total tagihan listrik tiap bulannya.[5]

Karena besarnya beban yang semakin tinggi tersebut maka seringkali dijumpai di pemerentah daerah banyak dijumpai tunggakan tagihan listrik untuk biaya listrik Lampu Penerangan Jalan Umum yang sangat besar. Pada penelitian yang saya lakukan ini, akan menggunakan suatu metode dengan cara membuat suatu metode/program untuk menghitung besarnya penggunaan energi listrik sebenarnya berdasarkan kebutuhan daya listrik yang dipasang untuk lampu penerangan jalan umum (LPJU) berdasarkan kelas jalan dan lebar jalan sesuai dengan 
peraturan yang berlaku di daerah tersebut., diharapkan dengan metode pada penelitian ini nantinya dapat dihitung kebutuhan investasi total yang dikeluarkan oleh pemerintah kota untuk biaya tagihan lampu penerangan jalan umum. $[3,6]$

\section{LANDASAN TEORI}

\subsection{Teknik Penerangan}

Di dalam teori teknik ilumnasi/penerangan terdapat beberapa istilah, simbol dan rumus-rumus perhitungan yang perlu dipahami bagi perancang lampu penerangan untuk menghasilkan perancangan penerangan yang lebih baik dan sesuai dengan penggunaanya. Istilahistilah dan persamaan-persamaan yang sering digunakan dalam perancangan teknik penerangan ditunjukkan sebagai berikut dibawah ini: [1,2]

\section{a. Fluks Cahaya}

Flux cahaya adalah jumlah energi yang diradiasikan dari suatu sumber cahaya setiap detik dalam bentuk gelombang cahaya. Jadi flux cahaya yang dapat dipancarkan oleh suatu sumber cahaya adalah seluruh jumlah cahaya yang dipancarkan dalam satu detik sesuai dengan persamaan berikut :

$$
\phi=\frac{Q}{t}
$$

dimana :

$\phi=$ flux cahaya satuan lumen ( $\mathrm{lm})$

$\mathrm{Q}=$ Energi cahaya satuan lumen jam atau lumen detik

$\mathrm{t}=$ waktu satuan jam atau detik

fluks cahaya yang diradiasikan oleh suatu sumber cahaya ialah jumlah seluruh cahaya yang dipancarkan selama satu detik. Bila sumber cahaya dimasukkan ke dalam reflektor, maka cahaya nantinya akan diarahkan, namun besarnya fluks cahaya akan tetap.

\section{b. Intensitas Cahaya}

Intensitas cahaya adalah kuat cahaya yang dikeluarkan oleh sebuah sumber cahaya ke arah tertentu dan diukur menggunakan fluxmeter dengan satuan Candela . Pada umumnya cahaya memiliki empat faktor yang dapat mempengaruhi kualitas pencahayaan yaitu kontras, silau, refleksi cahaya dan kualitas warna cahaya. Kemampuan mata manusia hanya dapat melihat cahaya dengan panjang gelombang tertentu yang diukur dalam besaran pokok ini. Persamaan Intensitas Cahaya sebagai berikut :

$$
\begin{aligned}
& I=\phi / \omega \\
& \phi=I x \omega
\end{aligned}
$$

dimana :

$$
\begin{aligned}
\phi & =\text { flux cahaya satuan lumen } \\
\mathrm{I} & =\text { intensits cahaya satuan candela }(\mathrm{cd}) \\
\omega & =\text { sudut ruang satuan steridian }(\mathrm{sr})
\end{aligned}
$$

\section{c. Iluminasi}

Banyaknya cahaya yang jatuh pada bidang kerja secara horizontal maupun vertikal, biasa disebut sebagai lighting level. Semakin besar arus cahaya maka makin kuat penerangan. Dengan intensitas cahaya yang sama, makin jauh jarak titik ukur dari sumber cahaya, makin kecil kuat penerangan yang terukur dengan harga satu per kuadrat jarak tertentu, Penerangan disebut juga iluminasi dengan persamaan berikut :

$$
E=\phi / A
$$

dimana :

$$
\begin{aligned}
& E=\text { illuminasi satuan } \operatorname{lux}(\mathrm{lx}) \\
& \mathrm{A}=\text { luas area bidang satuan }\left(\mathrm{m}^{2}\right)
\end{aligned}
$$

\section{d. Luminasi}

Luminansi adalah intensitas cahaya yang dipancarkan atau dipantulkan, oleh bidang permukaan kerja seluas S. Jika bidang seluas 1 $\mathrm{m}^{2}$ memancarkan cahaya berintensitas $1 \mathrm{~cd} \mathrm{ke}$ arah garis normal bidang, maka bidang tersebut memiliki luminansi sebesar sebagai berikut:

$$
\mathrm{B}_{\text {rata-rata }}=\frac{\mathrm{I}}{\mathrm{S}}
$$

dimana :

$$
\begin{aligned}
& \mathrm{B}=\text { Luminence } \\
& \mathrm{I}=\text { Luminous intensity }
\end{aligned}
$$$$
\mathrm{S}=\text { Area }
$$

\section{e. Efikasi Cahaya}

adalah perbandingan antar fluks cahaya lampu dengan besar daya listrik yang digunakan, persamaannya ditunjukkan sebagai berikut :

$$
K=\phi / P
$$

dimana: 
$\mathrm{K}=$ efikasi satuan lumen /watt (lm/watt)

$\mathrm{P}=$ daya listrik satuan watt $(\mathrm{w})$

\section{f. Efisiensi Cahaya}

Efisiensi cahaya adalah perbandingan fluks cahaya dengan fluks cahaya total yang dihasilkan lampu, persamaannya sebagai berikut:

$$
\eta=\phi / \phi_{m a k s}
$$

\section{g. Metode Lumen}

Metode ini cukup sederhana dan mudah sehingga untuk akan mempermudah dalam menghitung teknik penerangan. Dalam bentuk asalnya metode lumen mempunyai persamaan dasar pada persamaan (4). Untuk mencari nilai fluks total pada suatu area kerja bisa menggunakan persamaan 4 diatas dan untuk menghitung besarnya luminairnya bisa dipakai persamaan berikut :

$$
N=\phi_{t} / \phi_{L}
$$

dimana :

$$
\begin{aligned}
& \mathrm{N} \text { : jumlah luminair } \\
& \phi_{t} \text { : flux total yang dicari } \\
& \phi_{L} \text { : flux per luminair }
\end{aligned}
$$

\section{h. Metode Titik}

Penggunaan Metode titik untuk memastikan kalau iluminasi di semua bidang mencapai syarat minimal yang harus dipenuhi. Metode ini dilakukan di titik-titik yang memiliki nilai iluminasi rendah.

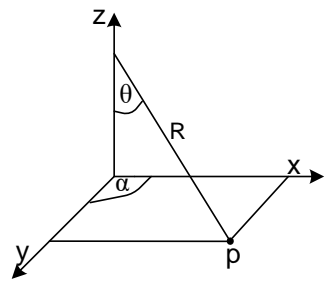

Gambar 1 Perhitungan iluminasi metode titik

Besar iluminasi pada titik dapat diseleseikan dengan persamaan berikut:

$$
\begin{gathered}
E=\frac{\phi}{R^{2}} \cos \theta \\
E=\frac{\phi}{\left(x^{2}+y^{2}+z^{2}\right)} \frac{h}{R}
\end{gathered}
$$

$$
E=\frac{\phi \cdot h}{\left(x^{2}+y^{2}+z^{2}\right)^{3 / 2}}
$$

\subsection{Penerangan jalan. $[2,3,6]$}

Penerangan jalan disesuaikan dengan Kelas jalan berdasarkan lebar jalan dan tingkat kepadatan lalu lintas yang lewat dikelompokkan beberapa tipe kelas jalan yaitu:

a. Kelas Jalan Arteri Primer

Merupakan kelas jalan yang diperuntukkan untuk kegiatan lokal dan regional dan lalu-lintas pemakai jalan sangat padat, sehingga diperlukan penerangan yang memenuhi syarat. Lux penerangan untuk kelas jalan ini adalah jenis lampu 50 lux,

b. Kelas jalan Arteri Sekunder

Diperuntukkan untuk kegiatan lokal dan regional dan kondisi lalu lintas cukup padat, sehingga diperlukan lampu adalah 50 lux.

\section{c. Kelsa Jalan Kolektor Primer}

Merupakan jalur pertemuan antara jalan lingkungan disekitarnya yang akan bertemu dengan jalan arteri primer atau arteri sekunder. Jenis lampu pada kelas jalan ini mempunyai 30 lux

\section{d. Kelas Jalan Kolektor Sekunder}

Merupakan jalan lingkungan yang akan bermuara pada jalur kelas jalan kolektor primer, jalan arteri primer atau kelas jalan sekunder Lux penerangan jenis dari kelas jalan ini, adalah 30 lux.

\section{e. Jalan Lingkungan}

Merupakan jalan- jalan di lingkungan pemukiman , pedesaan, gang atau perkampungan. Jenis lampu yang digunakan membutuhkan penerangan 15 lux.

\section{METODOLOGI PENELITIAN}

\subsection{Perancangan Program}

Sebelum merencanakan pembuatan program terlebih dahulu dibuat flowchart yang akan menunjukkan arah kerja program ini : 


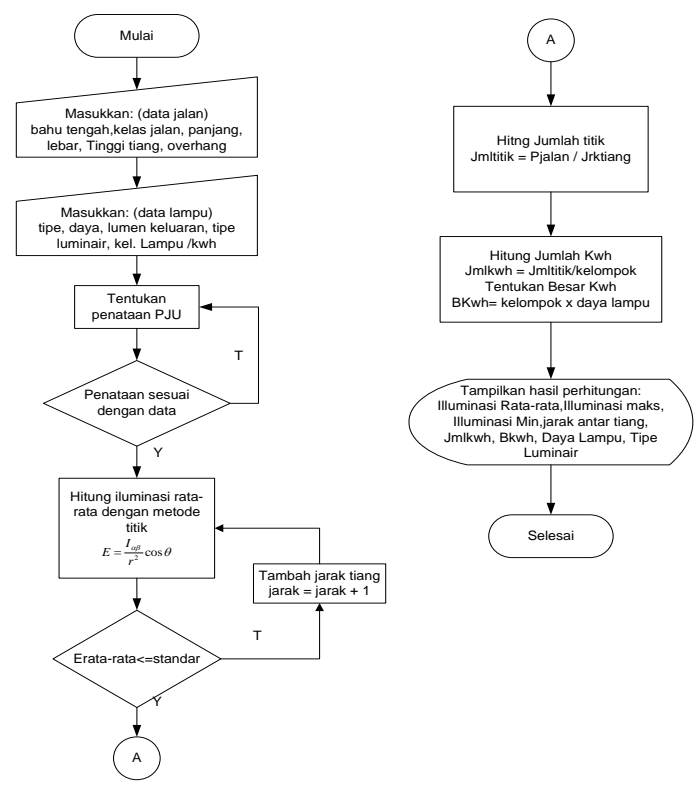

Gambar 2 flowchart program

\subsection{Penataan LPJU}

Perencanaan penataan lampu penerangan jalan mempertimbangkan aspek teknik, keindahan/estetika, dan aspek pembiayaan. Selain itu faktor data lalu lintas juga perlu dipertimbangkan, seperti :

a. Kondisi dua sisi jalan

b. Volume kendaraan dan pejalan kaki

c. Kejadian di malam hari (tabrakan antara kendaraan atau manusia)

d. Kejadian kejahatan pada malam hari

e. Banyaknya tikungan di jalan

f. Konstruksi pengerasan jalan

Terdapat beberapa kemungkinan dalam penataan letak lampu LPJU :

1. Jalan Satu Jalur

a. Jalur lampu LPJU satu sisi

Penataan lampu dimana luminer diarahkan di satu ruas sisi jalan.

b. Jalur lampu sig-sag

Penataan lampu ini dibuat sig-sag, metoda ini dipergunakan untuk jalan dengan lebar sama atau 1,5 kali ketinggian luminer.

c. Berhadapan

Penataan lampu ini dibuat berhadapan. Metoda ini digunakan untuk jalan dengan lebar sama atau 1,5 kali ketinggian luminer.

2. Jalan Dua Jalur a. Jalur tengah dengan luminer ganda dan jalur tepi dibuat berhadapan

b. Kombinasi jalur tengah dan berhadapan

Dalam upaya penataan dan meningkatkan efisiensi energi listrik, lampu penerangan jalan umum menggunakan peralatan teknologi hemat energi. Peralatan tersebut antara lain :

a. Penggunaan Elektronik Ballast

Digunakan elektonik ballast yang mempunyai kualitas baik dalam pencahayaan dan dapat melakukkan penghematan energi listrik

b. Penggunaan fotocell

Fotocell (LDR) atau sering disebut saklar cahaya bekerja apabila mendapat sinar yang memenuhi untuk perubahan tahanan maka kontaknya akan membuka (siang hari) bila cahaya yang diterimanya tidak memenuhi untuk kerja perubahan tahanan maka kontaknya akan menutup, sehingga lampu akan menyala (malam hari).

c. Penggunaan armatur lampu penerangan jalan dapat memberikan efek pantulan, tahan debu, dan mudah perawatannya.

Selain menggunakan jenis lampu yang hemat energi juga menggunakan peralatan yang memenuhi standar yang telah ditetapkan sehingga ada jaminan keamanan bagi manusia dan benda atau peralatan yang ada disekelilingnya.

a. Penggunaan KWH meter

Digunakan KWH meter yang telah lulus penteraan oleh PLN setempat.

b. Kontaktor

Saklar yang dilengkapi magnet penarik tuas kontak, bekerja apabila magnetnya dialiri arus sehingga akan menarik kontaknya mejadi tertutup (on).

c. $\mathrm{MCB}$

Miniature Circuit Breaker (MCB), pengaman yang dilengkapi sistem bimetal dan magnet. Dengan tegangan 220 volt dengan kemampuan arus:

1.2 A untuk daya 450 watt

2.4 A untuk daya 900 watt

3.6 A untuk daya 1300 watt

4.10 A untuk daya 2200 watt

5.16 A untuk daya 3500 watt

d. Konduktor

Menggunakan konduktor jenis outdoor. . 
e. Box Panel

Berisi alat-alat proteksi dan Kwh Meter dilengkapi lubang kabel dari bawah panel.

\subsection{Tarif Penerangan Jalan Umum}

Berdasarkan tariff dasar listrik Maret 2018 maka besarnya tarif untuk penerangan adalah sebesar Rp. 708,00 per KWh. Sedangkan pada penerangan jalan umum yang tidak dilengkapi KWh meter, maka perhitungan tarif diperhitungkan besar abonemennya

\subsection{Pemasangan Meteran}

Untuk menghasilkan penerangan yang baik dari segi penerangan maupun pembiayaan, maka dilakukan langkah-langkah agar dihasilkan penerangan jalan yang memadai dengan pembiayaan yang seminim mungkin. Langkah-langkah yang bisa diambil adalah dengan memasang Alat Pembatas dan Pengukur (APP), tujuannya adalah untuk mengetahui seberapa besar penggunaan daya listrik pada lampu LPJU tersebut, sehingga akan diketahui berapa biaya yang dikeluarkan. Karena bila tanpa Kwh meter biaya yang harus dibayar tiap bulan telah ditentukan tarifnya Gambar 2 berikut adalah salah satu contoh pemasangan KWh meter secara kelompok pada lampu penerangan jalan.

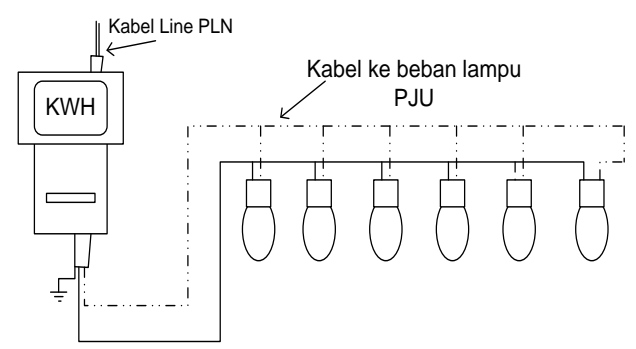

Gambar 2 Model pemasangan KWh meter

Pemasangan alat kWh meter bisa dilakukan secara kelompok atau bisa sendiri-sendiri. Dengan dipasangnya KWh meter untuk lampu LPJU diharapkan nantinya besar daya yang digunakan untuk penerangan jalan dapat diketahui dan besar biaya untuk rekening LPJU dapat dicatat berdasarkan angka yang terlihat di KWh meter bukan dengan abonemen.

\section{HASIL DAN PEMBAHASAN}

\subsection{Pengujian}

Pengujian program dilakukan dengan memasukkan data salah satu kelas jalan, kemudian dihitung dengan menggunakan program dan diperoleh hasil sebagai berikut:

- Data jalan

Tabel 1. Data Contoh Jalan

\begin{tabular}{|l|c|c|}
\hline \multicolumn{1}{|c|}{ Kelas jalan } & Panjang & lebar \\
\hline Arteri primer & $1000 \mathrm{~m}$ & $26 \mathrm{~m}$ \\
\hline Arteri Sekunder & $800 \mathrm{~m}$ & $20 \mathrm{~m}$ \\
\hline Kolektor primer & $650 \mathrm{~m}$ & $10 \mathrm{~m}$ \\
\hline Kolektor sekunder & $400 \mathrm{~m}$ & $8 \mathrm{~m}$ \\
\hline Jalan lingkungan & $200 \mathrm{~m}$ & $6 \mathrm{~m}$ \\
\hline
\end{tabular}

- Data penerangan

Tabel 2. Data penerangan

\begin{tabular}{|l|c|c|c|}
\hline \multicolumn{1}{|c|}{ Kelas jalan } & $\begin{array}{c}\text { Tinggi } \\
\text { gantung }\end{array}$ & Overhang & $\begin{array}{c}\text { Bahu } \\
\text { tengah }\end{array}$ \\
\hline Arteri primer & $12 \mathrm{~m}$ & $2 \mathrm{~m}$ & ada \\
\hline Arteri Sekunder & $9 \mathrm{~m}$ & $2 \mathrm{~m}$ & ada \\
\hline Kolektor primer & $9 \mathrm{~m}$ & $2 \mathrm{~m}$ & tidak \\
\hline Kolektor sekunder & $8 \mathrm{~m}$ & $2 \mathrm{~m}$ & tidak \\
\hline Jalan lingkungan & $7 \mathrm{~m}$ & $1 \mathrm{~m}$ & tidak \\
\hline
\end{tabular}

Dalam perhitungan akan dipakai lampu dengan tipe SON, dan HPL sebagai perbandingan dengan lumen yang hampir sama, dimana daya lampu disesuaikan dengan yang ada di pasaran.

Dari data kemudian dimasukkan dalam program perhitungan, berikut adalah contoh perhitungan untuk kelas jalan kolektor primer dengan menggunakan lampu tipe SON dan lampu tipe HPL :

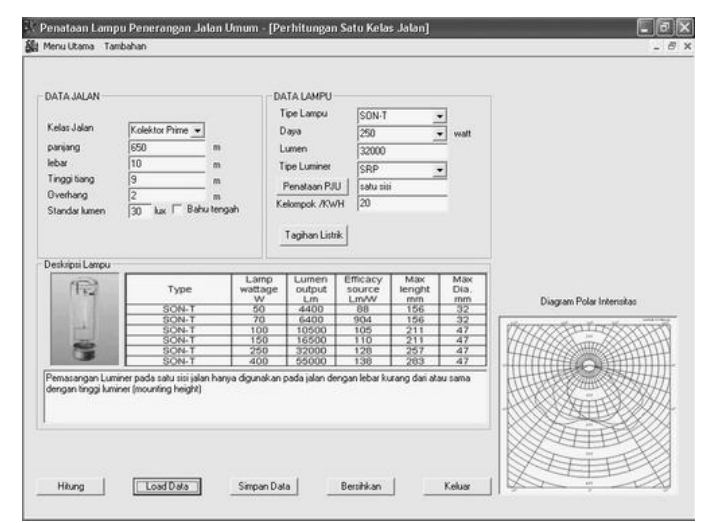

Gambar 3 Input program untuk kelas jalan kolektor primer

Dari perhitungan yang dilakukan program diperoleh hasil sebagai berikut, 


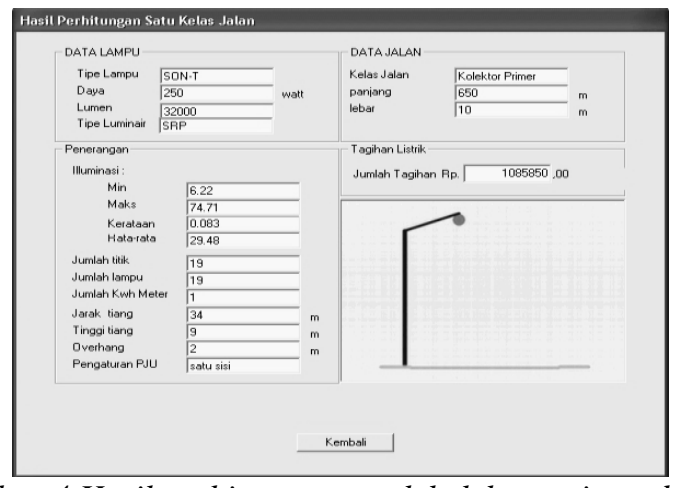

Gambar 4 Hasil perhitungan untuk kolektor primer dengan lampu SON 250W

Sebaran Illuminasi pada kelas jalan ini dapat dilihat pada gambar 5 berikut

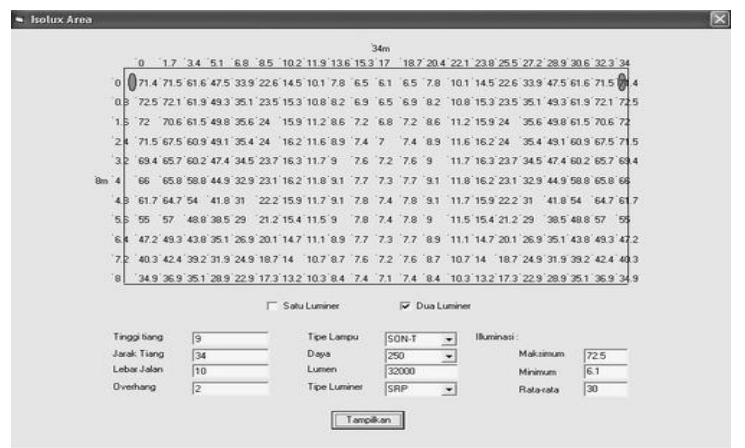

Gambar 5 Daerah sebaran intensitas penerangan dilihat dari dua lampu pada kelas jalan kolektor primer dengan lampu tipe SON $250 \mathrm{~W}$

Dari perhitungan yang sudah dilakukan dengan menggunakan lampu tipe SON250W, HPL $400 \mathrm{~W}$, dan lampu dengan tiang terpasang mengikuti tiang jaringan listrik, dengan asumsi jarak antar tiang jaringan $50 \mathrm{~m}$ maka dapat dibuat suatu tabel perbandingan sebagai berikut :
Tabel 3 Perbandingan hasil pengujian

\begin{tabular}{|c|c|c|c|}
\hline Perbandingan & \multicolumn{2}{|c|}{ Dengan APP } & Tanpa APP \\
\hline Kelas jalan & Kolektor Primer & Kolektor Primer & Kolektor Primer \\
\hline Tipe Lampu & SON-T & HPL-N & HPL-N \\
\hline Daya lampu & $250 \mathrm{~W}$ & $400 \mathrm{~W}$ & $400 \mathrm{~W}$ \\
\hline Lumen & $32000 \mathrm{~lm}$ & $22000 \mathrm{~lm}$ & $22000 \mathrm{~lm}$ \\
\hline Jarak tiang & $34 \mathrm{~m}$ & 23 & $50 \mathrm{~m}$ \\
\hline $\begin{array}{c}\text { Illuminasi } \\
\text { rata-rata }\end{array}$ & $29,48 \mathrm{lux}$ & $29,58 \mathrm{lux}$ & $13,91 \mathrm{lux}$ \\
\hline $\begin{array}{c}\text { Illuminasi } \\
\text { maks. }\end{array}$ & $74,71 \mathrm{lux}$ & $52,79 \mathrm{lux}$ & $51,04 \mathrm{lux}$ \\
\hline $\begin{array}{c}\text { Illuminasi } \\
\text { min. }\end{array}$ & $6,22 \mathrm{lux}$ & $13,26 \mathrm{lux}$ & $1,26 \mathrm{lux}$ \\
\hline Kerataan & 0,08 & 0,25 & 0,03 \\
\hline $\begin{array}{c}\text { Tagihan } \\
\text { listrik }\end{array}$ & $\mathrm{Rp} .1 .085 .850,00$ & $\mathrm{Rp} .2 .560 .320,00$ & $\begin{array}{c}\text { Rp. } 3.095 .625, \\
00\end{array}$ \\
\hline $\begin{array}{c}\text { Jumlah } \\
\text { Lampu }\end{array}$ & $19 \mathrm{~m}$ & $23 \mathrm{~m}$ & $50 \mathrm{~m}$ \\
\hline Tinggi tiang & $9 \mathrm{~m}$ & $9 \mathrm{~m}$ & $9 \mathrm{~m}$ \\
\hline
\end{tabular}

Dari Tabel 3 terlihat bahwa dengan pengaturan (dengan APP) dan menggunakan lampu tipe SON 250 $\mathrm{W}$ akan menghasilkan penerangan dengan penerangan lebih baik dan biaya yang dikeluarkan lebih kecil, dan jarak optimal yang lebih jauh jika dibandingkan dengan lampu HPL 400W, hal ini disebabkan karena lampu tipe SON mengeluarkan fluks cahaya yang lebih besar dibandingkan dengan lampu Tipe HPL. Sedangkan jika lampu penerangan jalan tanpa menggunakan APP seperti yang telah ada selama ini dan menggunakan lampu tipe HPL, maka dengan penerangan dengan kualitas jauh dibawah standar dan biaya yang jauh lebih mahal.

Untuk mengetahui besarnya kebutuhan penerangan jalan dalam suatu wilayah dapat menggunakan perhitungan, perhitungan dalam wilayah ini didasarkan untuk daerah berdasarkan kelas jalan i yang sudah disediakan pada program ini. Berikut adalah salah satu contoh penggunaan perhitungan kebutuhan untuk penerangan jalan di satu wilayah,

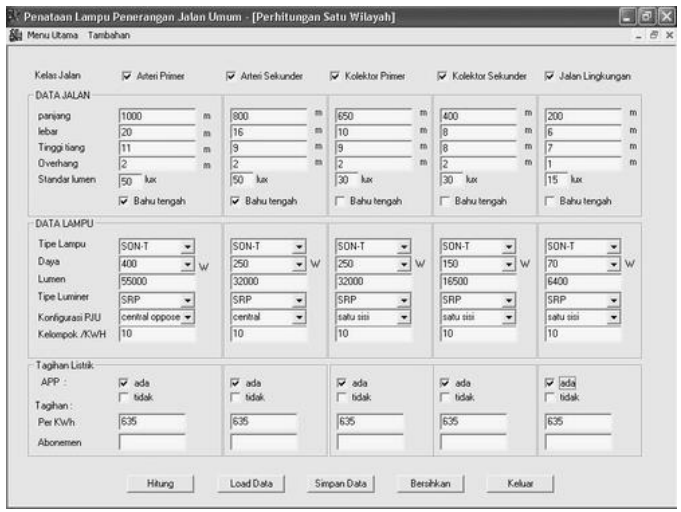


Gambar 6 Data masukkan untuk perhitungan suatu wilayah dengan menggunakan Kwh meter

Dengan menggunakan data masukkan tersebut akan dihasilkan perhitungan untuk suatu wilayah, seperti terlihat pada gambar 7 berikut ini,

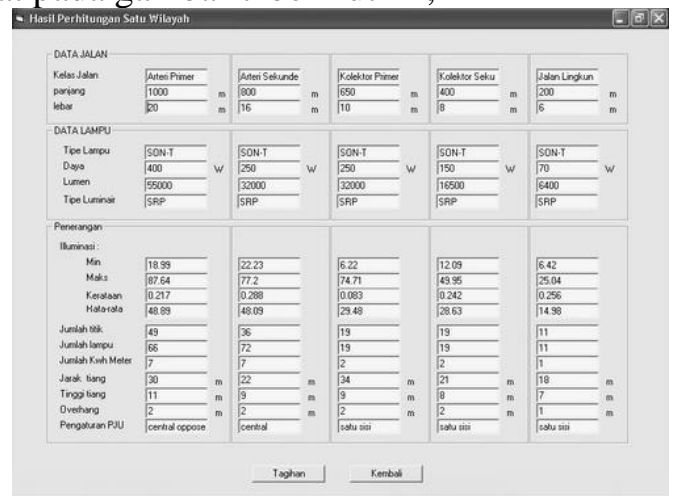

Gambar 7 Kebutuhan penerangan jalan di suatu wilayah

Besarnya tagihan listrik yang merupakan beban pemerintah daerah jika lampu penerangan jalan tersebut dilengkapi dengan APP dapat terlihat pada Gambar 8 berikut,

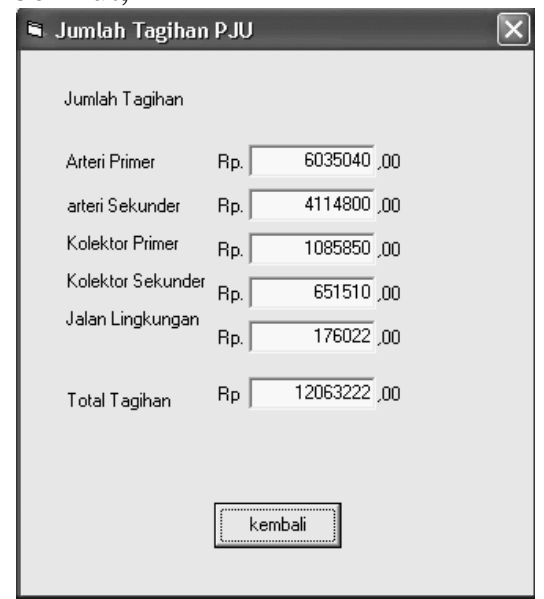

Gambar 8 Jumlah tagihan listrik, pengaturan penerangan dengan APP

Sedangkan bila tanpa dilengkapi APP maka besarnya tagihan adalah,

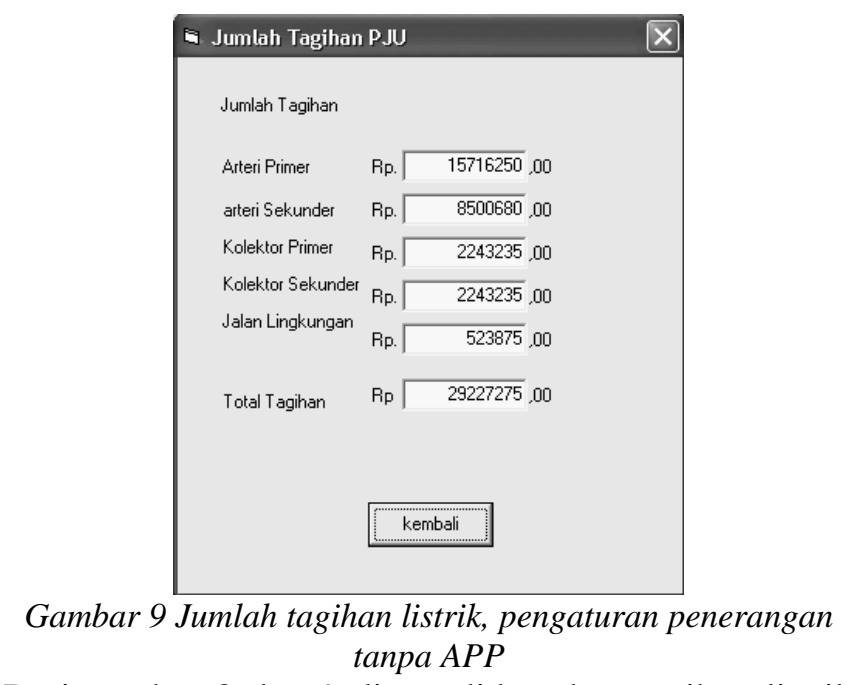

Dari gambar 8 dan 9 diatas didapatkan tagihan listrik yang lebih besar bila tidak dilengkapi dengan APP, hal tersebut disebabkan adanya metode dengan penghitungan tagihan listrik dengan abonemen akan memperhitungkan besarnya daya lampu yang digunakan

Berdasarkan contoh beberapa kelas jalan, terlihat dengan penggunaan KWh meter akan meningkatkan menurunkan biaya tagihan penggunaan energi listrik yang dikeluarkan, dan dengan digunakannya metode pengaturan untuk penerangan jalan dan menggunakan jenis lampu dengan lumen keluaran lebih besar diperoleh penerangan yang memenuhi syarat serta biaya yang dikeluarkan lebih rendah.

\section{SIMPULAN}

Hasil dari pengujian program ini, dapat disimpulkan sebagai berikut:

Lampu penerangan jalan liar atau tanpa APP akan memberatkan pemerintah daerah dalam membayar tagihan listrik penerangan jalan dan bila tidak dilengkapi dengan Kwh Meter dalam penghitungan didapatkan tagihan listrik akan lebih besar dibanding dengan lampu dengan dilengkapi Kwh meter

Dengan metode penataan lampu penerangan jalan akan mengoptimalkan jarak pengaturan akan diperoleh suatu penerangan jalan dengan kualitas yang sesuai dengan standar yang sudah dibakukan

\section{KEPUSTAKAAN}

[1] Christian D., Lestari P.. Teknik Pencahayaan dan Tata Letak Lampu. Artolite-Grasindo. 2013 
[2] Asnal Effendi, Niko Razonta. "Penataan dan meterisasi lampu penerangan jalan umum (lpju) desa apar kecamatan pariaman utara, Jurnal Teknik Elektro ITP Volume 4 No. 1; Januari 2015

[3] Rakadifa E , Sudjantyo H, Lamtiar S, Rancangan Pemasangan Lampu Penerangan Jalan Menuju Masjid Rauda Datul, Jurnal Ilmiah Aviasi Langit Biru Vol. 10 NO 3 Oktober 2017

[4] McGuinness, William J.. Mechanical and Electrical Equipment for Buildings. $6^{\text {th }}$ Ed. John Wiley and Sons. 2013

[5] Sity Safridha L, Mekanisme Pemungutan Pajak Penerangan Jalan Di Dinas Pertamanan Kota Medan, Fakultas Ilmu Sosial Dan Ilmu Politik Universitas Sumatera Utara Medan. 2010

[6] Badan Standardisasi Nasional, " RSNI S-XX2006 Spesifikasi Penerangan Jalan di Kawasan Perkotaan", Standar Nasional Indonesia, Jakarta, 8, 2005

[7] NN. Efficient Street Lighting Design Guide. Connecticut Light and Power Company. Connecticut, North America. 2013

[8] NN.. Special Specifications For The Construction Of Street Lighting Systems. Department Of Public Works. Los Angeles, 2014

[9] P. Van Harten.. Instalasi Arus Kuat 1,2,3. Bina Cipta, Bandung. 2011

[10] Leatman Trading, "Philips SON-T Plus 400 watt bloom bulb, 2006 